\title{
DESEMPENHO DE UM CONJUNTO TRATOR-ESCARIFICADOR EM DOIS TEORES DE ÁGUA DO SOLO E DUAS PROFUNDIDADES DE TRABALHO
}

\author{
Ariel Muncio Compagnon ${ }^{1}$, Carlos Eduardo Angeli Furlani ${ }^{2}$, Kauê Alves Oshiro ${ }^{3}$, Rouverson Pereira da Silva ${ }^{4}$, \\ Marcelo Tufaile Cassia ${ }^{5}$
}

RESUMO

O dimensionamento do conjunto trator-implemento relaciona-se com o desempenho operacional. A demanda energética na operação agrícola é importante para o planejamento e estimativa dos custos de produção da cultura. Com este trabalho objetivou-se avaliar o desempenho operacional do conjunto trator-escarificador de 7 hastes, em função do teor de água do solo e profundidade de trabalho, em um Latossolo Vermelho. Foi utilizado um esquema fatorial inteiramente casualizado $(2 \times 2)$ com 5 repetições, em que o teor de água do solo define o tratamento principal (26,2 e 21,9\%), e a profundidade de escarificação define o tratamento secundário $(0,20$ e $0,30 \mathrm{~m})$. A área útil de cada parcela foi de $200 \mathrm{~m}^{2}(40 \times 5 \mathrm{~m})$. Os dados foram submetidos à análise de variância e ao teste de comparação de médias de Tukey, a 5\% de probabilidade. As variáveis analisadas foram: velocidade de trabalho; consumo horário e operacional de combustível, capacidade de campo operacional; força e potência na barra de tração; e patinagem dos rodados traseiros e dianteiros. A velocidade de trabalho foi afetada pela interação teor de água do solo e profundidade de trabalho. As variáveis relacionadas ao consumo de combustível e a patinagem dos rodados dianteiros foram influenciadas pelo teor de água do solo e profundidade de trabalho. A força e a potência na barra de tração aumentaram com a profundidade, enquanto que a capacidade de campo operacional aumentou no menor teor de água do solo.

Palavras-chave: consumo de combustível, força de tração, mecanização agrícola, preparo do solo

\begin{abstract}
\section{PERFORMANCE OF TRACTOR CHISEL PLOW AT TWO LEVELS OF SOIL WATER CONTENT AND TWO DEPTHS OF SCARIFICATION}

The dimensioning of the agricultural tractor and implements is related to the operating performance. The energy demand of a particular agricultural operation is important for planning and estimating the costs of crop production. The objective of this study was to evaluate the operational performance of the tractor-chisel plow, 7 spindles, depending on soil water content and work depth, on Oxisol. The experimental design was completely randomized $(2 \times 2)$ with 5 replicates in the soil, where the water content defines the major treatment (26.2 and $21.9 \%)$ and scarification depth defines the secondary treatment $(0.20$ and $0.30 \mathrm{~m})$. The floor area of each plot was $200 \mathrm{~m}^{2}(40 \times 5 \mathrm{~m})$. The data were submitted to ANOVA and mean comparison Tukey test at 5\% probability. The variables analyzed were: work speed; hours and operational consumption of fuel; operating field capacity; force and power in the drawbar; and the skating the front and rear axles. The work speed was affected by the interaction between soil water content and work depth. The variables related to the fuel consumption and the slipping of front axles were influenced by soil water content and work depth. The force and power in drawbar increased with the depth, while the operating field capacity has increased in the lowest soil water content.
\end{abstract}

Keywords: fuel consumption, traction force, agricultural mechanization, soil tillage

\footnotetext{
Recebido para publicação em 13/09/2012. Aprovado em 22/11/2012.

1 - Engenheiro Agrícola, Estudante de doutorado da UNESP/FCAV/Jaboticabal-SP, arielcompagnon@gmail.com

2 - Engenheiro Agrônomo, Professor, Departamento de Eng. Rural, UNESP/FCAV/Jaboticabal-SP, furlani@fcav.unesp.br

3 - Estudante de Agronomia, UNESP/FCAV/Jaboticabal-SP, kaue_oshiro@hotmail.com

4 - Engenheiro Agrícola, Professor, Departamento de Eng. Rural, UNESP/FCAV/Jaboticabal-SP, rouverson@fcav.unesp.br

5 - Engenheiro Agrônomo, Estudante de doutorado da UNESP/FCAV/Jaboticabal-SP, marcelocassia@gmail.com
}

52 REVENG 52-58p. 


\section{INTRODUÇ̃̃O}

Uma das principais funções dos tratores agrícolas é transformar a energia química contida nos combustíveis e fornecê-la na forma de energia mecânica, por meio da força produzida na barra de tração, utilizada para tracionar máquinas e implementos agrícolas (MONTEIRO, 2008).

Algumas pesquisas indicam que o teor de água do solo e profundidade de trabalho são variáveis que influenciam nas operações de preparo de solo. Maiores conhecimentos e domínios podem levar à redução dos custos de produção das culturas (KICHLER et al., 2007).

Para se avaliar o desempenho operacional de escarificadores podem ser utilizados parâmetros como profundidade e largura de trabalho, velocidade de deslocamento, consumo de combustível, força de tração e patinagem (SASAKI \& GONÇALVES, 2005). Salvador et al. (2008) afirmam que a menor patinagem dos rodados motrizes proporciona menor compactação do solo, menor desgaste dos pneus e dos mecanismos de transmissão, como também reduz os gastos adicionais de combustíveis.

Levien et al. (2003), ao avaliarem o desempenho operacional de métodos de preparo de solo, observaram que a capacidade operacional no preparo reduzido do solo com escarificador foi três vezes maior, bem como demandou $21 \%$ menos potência e $52 \%$ menos combustível, por área trabalhada, quando comparado com o preparo convencional.

Estudando o desempenho energético de subsoladores, Kichler et al. (2007) observaram que ocorreu aumento no consumo de combustível de $20 \%$ e incremento na força de tração de $120 \%$ quando se aumentou a profundidade de $0,23 \mathrm{~m}$ para $0,35 \mathrm{~m}$.

Gabriel Filho et al. (2008) citam a necessidade de maior quantidade de pesquisas para avaliar o desempenho em tração sob condições de campo e, com isso, fornecer informações suficientes para que o desempenho seja estimado.

Partindo da hipótese de que o teor de água do solo afetará o desempenho operacional nas profundidades de trabalho, objetivou-se com o presente trabalho avaliar o desempenho operacional do conjunto trator-escarificador em função do teor de água do solo e da profundidade de trabalho.

\section{MATERIAL E MÉTODOS}

O experimento foi realizado no mês de outubro de 2011, na área experimental da Fazenda de Ensino, Pesquisa e Produção da FCAV/UNESP, em Jaboticabal, SP, localizada nas coordenadas geodésicas $21^{\circ} 14^{\prime}$ ' latitude $\mathrm{S}$ e $48^{\circ} 17^{\prime}$ ' longitude $\mathrm{W}$, com altitude média de $560 \mathrm{~m}$, clima Aw, de acordo com a classificação climática de Köeppen (1948) e declividade média de 4\%. O solo da área experimental é classificado como latossolo vermelho eutroférrico típico textura argilosa, de acordo com o Sistema Brasileiro de Classificação dos Solos (ANDREOLI \& CENTURION, 1999), com granulometria de $50 \%$ de argila, $25 \%$ de limo e $25 \%$ de areia.

Anteriormente ao experimento, realizou-se a colheita de milho e a área permaneceu em pousio, sem a presença de plantas daninhas, porém, com massa seca residual de milho em torno de $3 \mathrm{Mg}^{-}$ ${ }^{1}$. Foi utilizado o delineamento em esquema fatorial inteiramente casualizaado $(2 \times 2)$ com 5 repetições, em que o teor de água do solo define o tratamento principal $(26,2 \%$ e $21,9 \%)$, e a profundidade de escarificação define o tratamento secundário $(0,20$ e $0,30 \mathrm{~m}$ ). A área útil de cada parcela foi de 200 $\mathrm{m}^{2}(40 \mathrm{~m} \times 5 \mathrm{~m})$. As variáveis analisadas foram: velocidade de trabalho; consumo horário e específico de combustível; capacidade de campo operacional; força e potência na barra de tração; patinagem dos rodados traseiros e dianteiros.

Para obter os dois teores de água, as parcelas do tratamento de $26,2 \%$ foram irrigadas com aspersores durante cinco horas até o solo chegar próximo à capacidade de campo; o tratamento de $21,9 \%$ não foi irrigado. Na área irrigada, aguardou-se dois dias para realizar a escarificação das parcelas, para infiltração e homogeneização da água no solo.

Foram coletadas amostras de solo em um ponto por parcela no momento da escarificação, para determinação do teor de água dos tratamentos, com auxílio de trado holandês, nas profundidades de $0-0,10 \mathrm{~m} ; 0,10-0,20 \mathrm{~m}$ e $0,20-0,30 \mathrm{~m}$. As amostras foram acondicionadas em latas de alumínio e posteriormente levadas para secagem em estufa a 
$105{ }^{\circ} \mathrm{C}$ até obter massa constante, possibilitando o cálculo do teor de água segundo o método gravimétrico padrão descrito em Embrapa (1997). Os teores foram $26,2 \%$ e $21,9 \%$, e constatou-se homogeneidade nas camadas de solo das parcelas.

Para a operação de escarificação do solo, foi utilizado um trator da marca Valtra, modelo BM 125i, 4 × 2 TDA, com potência máxima de 91,9 $\mathrm{kW}(125 \mathrm{cv})$ no motor à $2.300 \mathrm{rpm}$, com pneus dianteiros Firestone Super All Traction 14.9 - 26 R1, 6 lonas, com pressão de insuflagem de 137,9 $\mathrm{kPa}$ (20 psi); e traseiros Goodyear Gyna Torque III 23.1 - 30 R1, 12 lonas, com pressão de insuflagem de $165,5 \mathrm{kPa}$ (24 psi), o qual trabalhou na marcha $2^{\mathrm{a}} \mathrm{L}$ à $2.100 \mathrm{rpm}$, com velocidade média de $3,9 \mathrm{~km}$ $\mathrm{h}^{-1}$, e um escarificador Marchesan, modelo AST/ MATIC 450, com massa total de $1.400 \mathrm{~kg}$. Esse equipamento é constituído por sete hastes espaçadas de $0,45 \mathrm{~m}$, com ponteira sem asa de $0,07 \mathrm{~m}$ de largura, o que habilita o trabalho em profundidades de até $0,49 \mathrm{~m}$, pois se considera que a profundidade máxima de trabalho deve ser de 5 a 7 vezes a largura da ponteira (SPOOR \& GODWIN, 1978). A largura útil de trabalho do escarificador é de 3,15 $\mathrm{m}$, e este está equipado com discos de corte de palha para cada haste com diâmetro de $0,457 \mathrm{~m}$ (18 pol), sistema de segurança de desarme automático e rolo destorroador. O controle de profundidade é feito pelos pneus do escarificador, com o auxílio de anéis presos ao pistão hidráulico.

Para realizar a aquisição e armazenamento dos dados referentes às variáveis analisadas, foi utilizado um sistema composto por Micrologger CR23X produzido pela Campbell Scientific Inc. Para determinação do consumo horário de combustível, utilizou-se um sistema composto de dois conjuntos de medição, sendo um para a alimentação da bomba injetora e o outro de retorno, obtendo-se o volume realmente utilizado pelo trator durante o percurso, marca Oval M - III, modelo LSF41. Os valores de fluxo de combustível foram obtidos em mililitros e extrapolados para litros. Com base no volume consumido e no tempo de percurso em cada parcela, foi determinado o consumo de combustível horário e operação conforme equação (1).

$C h=\left(\frac{V a-V r}{t}\right) \times 3,6$ em que

$\mathrm{Ch}=$ consumo de combustível horário $\left(\mathrm{L} \mathrm{h}^{-1}\right)$;

$\mathrm{Va}=$ volume de alimentação de combustível na entrada da bomba injetora $(\mathrm{mL})$;

$\mathrm{Vr}=$ volume total retornado dos bicos e da bomba injetora $(\mathrm{mL})$;

$\mathrm{t}=$ tempo de percurso na parcela $(\mathrm{s})$; e

3,6 = fator de conversão.

O consumo de combustível operacional foi calculado com base no consumo horário e na capacidade de campo operacional, sendo expresso em L ha-1, conforme equação (2).

$\mathrm{Co}=\frac{\mathrm{Ch}}{\mathrm{Cco}}$

em que

$\mathrm{Co}=$ consumo de combustível operacional $\left(\mathrm{L} \mathrm{ha}^{-1}\right)$; $\mathrm{Ch}=$ consumo de combustível horário $\left(\mathrm{L} \mathrm{h}^{-1}\right)$; e $\mathrm{Cco}=$ capacidade de campo operacional $\left(\mathrm{ha}^{-1}\right)$.

A capacidade de campo operacional foi obtida em função da largura de trabalho do escarificador, da velocidade do conjunto trator-escarificador, e da eficiência da operação, a qual foi adotada para efeito de cálculo como sendo $75 \%$, conforme equação (3).

$C C O=\left(\frac{v \times L \theta}{10}\right) \times e$

em que

$\mathrm{Cco}=$ capacidade de campo operacional $\left(\mathrm{ha} \mathrm{h}^{-1}\right)$; $\mathrm{v}=$ velocidade real de deslocamento do conjunto trator-escarificador $\left(\mathrm{km} \mathrm{h}^{-1}\right)$;

$\mathrm{Le}=$ largura útil de trabalho do escarificador (m); $\mathrm{e}=$ eficiência (decimal); e

$10=$ fator de conversão de unidades.

A força requerida na barra de tração foi medida utilizando-se célula de carga marca Shimizu, modelo TF 400, com capacidade de $100 \mathrm{kN}$ e precisão de $\pm 1 \mathrm{~N}$, instalada sobre um suporte entre a barra de tração do trator e o cabeçalho do escarificador. As aquisições foram realizadas a cada segundo. Os dados foram obtidos em $\mathrm{kgf}$ e

\section{REVENG}


convertidos para kN. De posse dos dados, calculouse o valor médio da força de tração de cada parcela experimental. A potência média na barra de tração $(\mathrm{kW})$ foi determinada pelo produto da força $(\mathrm{kN})$ pela velocidade $\left(\mathrm{m} \mathrm{s}^{-1}\right)$. Esta velocidade foi mensurada utilizando-se um radar marca Dickey John, modelo RVS II, instalado na lateral direita do trator, disposto em ângulo de $45^{\circ}$ com a horizontal, à freqüência de $1 \mathrm{~Hz}$.

A patinagem dos rodados dianteiros e traseiros foi determinada da seguinte forma: (1) marcaramse com o giz os flancos de um pneu dianteiro e outro traseiro do trator; (2) com o trator em movimento numa área não trabalhada e com o escarificador levantado, cravaram-se duas balizas (uma para cada pneu) no local onde as marcas de giz dos pneus coincidiram com o solo; (3) cravaram-se mais duas balizas quando foram completadas 10 voltas de cada pneu; (4) mediram-se as distâncias percorridas pelos dois pneus (d0); repetiu-se os passos 2, 3 e 4, porém, agora com o trator em operação nas parcelas experimentais (d1). Assim, a patinagem foi determinada pela equação (4).

$P=\frac{d 0-d 1}{d 0} \times 100$

em que
$\mathrm{P}=$ patinagem dos rodados $(\%)$

$\mathrm{d} 0=$ distância percorrida pelas rodas sem carregamento (m); e

d1 = distância percorrida pelas rodas em operação (m).

$\mathrm{O}$ efeito dos fatores principais e de suas interações foram avaliados pela análise de variância (ANOVA) a $5 \%$ de probabilidade. Quando o teste $\mathrm{F}$ foi significativo, as médias foram comparadas pelo teste de Tukey, a 5\% de probabilidade de erro, com uso do programa estatístico Sisvar 5.3 (FERREIRA, 2008).

\section{RESULTADOS E DISCUSSÃO}

A velocidade de trabalho foi afetada tanto pelo teor de água do solo quanto pela interação deste fator com a profundidade de escarificação (Quadro 1). Os dados foram desdobrados e estão apresentados no Quadro 2. As variáveis relacionadas ao consumo de combustível e a patinagem dos rodados dianteiros foram influenciadas pelo teor de água do solo e pela profundidade de escarificação. A força e a potência na barra de tração aumentaram com a profundidade de trabalho, enquanto que a Cco foi afetada apenas pelo teor de água do solo (Quadro 1).

Quadro 1. Análise de variância e teste de médias para velocidade de trabalho; consumo horário e operacional de combustível; capacidade de campo operacional; força e potência na barra de tração; e patinagem traseira e dianteira

\begin{tabular}{|c|c|c|c|c|c|c|c|c|}
\hline \multirow[b]{2}{*}{ FATORES } & \multirow[b]{2}{*}{$\begin{array}{c}\text { Veloci- } \\
\text { dade } \\
\left(\mathbf{k m ~ h}^{-1}\right)\end{array}$} & \multicolumn{2}{|c|}{ Consumo de combustível } & \multirow{2}{*}{$\begin{array}{c}\text { Força } \\
\text { de } \\
\text { tração } \\
(k N)\end{array}$} & \multirow[b]{2}{*}{$\begin{array}{c}\text { Potência } \\
\text { na barra } \\
(\mathbf{k W})\end{array}$} & \multirow[b]{2}{*}{$\begin{array}{c}\text { Cco }^{1} \\
\left(\mathrm{ha} \mathrm{h}^{-1}\right)\end{array}$} & \multicolumn{2}{|c|}{ Patinagem } \\
\hline & & $\begin{array}{c}\text { Horário } \\
\left(\mathbf{L ~ h}^{-1}\right)\end{array}$ & $\begin{array}{c}\text { Operacional } \\
\left(\mathbf{L ~ h a}^{-1}\right)\end{array}$ & & & & $\begin{array}{c}\text { Traseira } \\
(\%)\end{array}$ & $\begin{array}{c}\text { Dianteira } \\
(\%)\end{array}$ \\
\hline \multicolumn{9}{|c|}{ Teor de água do solo (T) } \\
\hline $\begin{array}{l}26,2 \% \\
21,9 \% \\
\end{array}$ & $\begin{array}{l}3,86 \\
3,94 \\
\end{array}$ & $\begin{array}{l}10,50 \mathrm{~b} \\
10,01 \mathrm{a}\end{array}$ & $\begin{array}{l}11,76 \mathrm{~b} \\
11,00 \mathrm{a}\end{array}$ & $\begin{array}{l}18,98 \mathrm{a} \\
17,83 \mathrm{a}\end{array}$ & $\begin{array}{l}19,50 \mathrm{a} \\
20,36 \mathrm{a}\end{array}$ & $\begin{array}{l}0,89 \mathrm{a} \\
0,91 \mathrm{~b}\end{array}$ & $\begin{array}{l}8,31 \mathrm{a} \\
7,27 \mathrm{a} \\
\end{array}$ & $\begin{array}{l}7,95 \mathrm{~b} \\
7,20 \mathrm{a} \\
\end{array}$ \\
\hline \multicolumn{9}{|c|}{ Profundidade de trabalho $(\mathrm{P})$} \\
\hline $\begin{array}{l}0,20 \mathrm{~m} \\
0,30 \mathrm{~m} \\
\end{array}$ & $\begin{array}{l}3,92 \\
3,88 \\
\end{array}$ & $\begin{array}{l}10,00 \mathrm{a} \\
10,51 \mathrm{~b} \\
\end{array}$ & $\begin{array}{l}11,03 \mathrm{a} \\
11,72 \mathrm{~b}\end{array}$ & $\begin{array}{l}17,40 \mathrm{a} \\
19,42 \mathrm{~b}\end{array}$ & $\begin{array}{l}18,94 \mathrm{a} \\
20,92 \mathrm{~b}\end{array}$ & $\begin{array}{l}0,91 \mathrm{a} \\
0,90 \mathrm{a} \\
\end{array}$ & $\begin{array}{l}7,86 \mathrm{a} \\
7,71 \mathrm{a} \\
\end{array}$ & $\begin{array}{l}6,85 \mathrm{a} \\
8,30 \mathrm{~b} \\
\end{array}$ \\
\hline \multicolumn{9}{|l|}{ Teste de $\mathrm{F}$} \\
\hline $\begin{array}{l}\mathrm{T} \\
\mathrm{P} \\
\mathrm{T} \times \mathrm{P} \\
\mathrm{CV}(\%)\end{array}$ & $\begin{array}{c}8,692^{*} \\
2,292^{\mathrm{ns}} \\
4,629^{*} \\
1,44\end{array}$ & $\begin{array}{c}4,551^{*} \\
5,005^{*} \\
0,028^{\mathrm{ns}} \\
5,04 \\
\end{array}$ & $\begin{array}{c}7,511^{*} \\
6,232^{*} \\
0,195^{\text {ns }} \\
5,47\end{array}$ & $\begin{array}{c}2,052^{\text {ns }} \\
6,443^{*} \\
0,798^{\text {ns }} \\
9,73\end{array}$ & $\begin{array}{c}1,135^{\text {ns }} \\
5,966^{*} \\
0,335^{\text {ns }} \\
9,09 \\
\end{array}$ & $\begin{array}{c}4,723^{*} \\
2,410^{\mathrm{ns}} \\
3,470^{\mathrm{ns}} \\
1,60 \\
\end{array}$ & $\begin{array}{c}2,282^{\mathrm{ns}} \\
0,051^{\mathrm{ns}} \\
1,283^{\mathrm{ns}} \\
19,74 \\
\end{array}$ & $\begin{array}{c}4,561^{*} \\
16,702^{*} \\
3,430^{\text {ns }} \\
10,41 \\
\end{array}$ \\
\hline
\end{tabular}

Em cada coluna, para cada fator, médias seguidas de mesmas letras não diferem entre si, pelo teste de Tukey, a $5 \%$ de probabilidade.

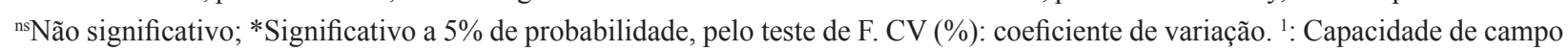
operacional. 
Quando o solo está mais seco, tende a haver maior atrito com os pneus, causado pela sustentação do solo, fazendo com que o conjunto tratorescarificador desloque com maior velocidade do que quando o solo está mais úmido, mantendo-se à mesma marcha e rotação de trabalho, fato este observado para a profundidade de $0,30 \mathrm{~m}$ (Quadro 2). O solo com maior teor de umidade permite ao rodado aprofundar mais e assim aumentar a resistência ao rolamento, diminuindo a velocidade de trabalho. Este fato também foi observado por Sasaki \& Gonçalves (2005), que trabalharam com subsolador de haste única em três tipos de Latossolo Vermelho, de textura média, argilosa e muito argilosa. Na menor profundidade, o teor de água do solo não alterou a velocidade de trabalho.

Para o teor de água de $26,2 \%$, a velocidade de trabalho foi maior na profundidade mais superficial, devido à menor resistência oferecida pelo equipamento de hastes. Para o teor de 21,9\%, este fato não foi observado.

O consumo horário de combustível (Quadro 1) foi $4,8 \%$ superior quando o teor de água do solo aumentou. Esses resultados discordam dos observados por Reis et al. (2002), que não obtiveram diferenças em trabalho com duas semeadorasadubadoras na cultura do milho, com 4 teores de água do solo em argissolo vermelho-amarelo, com textura argilosa. Para o fator profundidade de trabalho, o consumo horário de combustível aumentou $5 \%$ quando a profundidade passou de 0,20 para $0,30 \mathrm{~m}$, devido ao aumento da área mobilizada do solo pelas hastes escarificadoras

O consumo operacional diferiu para os fatores teor de água do solo e profundidade de trabalho, semelhante ao que aconteceu com o consumo horário. Como o consumo operacional é função da capacidade de campo operacional (Cco), observouse que o aumento no teor de água do solo reduziu a Cco, aumentando o consumo operacional. Para a profundidade de trabalho, houve maior consumo para a profundidade de $0,30 \mathrm{~m}$, em função da maior força de tração exigida pelo equipamento de hastes para vencer a resistência oferecida pelo solo.

A força de tração não apresentou diferença para o teor de água do solo, obtendo valor médio de 18,41 $\mathrm{kN}$, pois a força de coesão das partículas do solo não é influenciada pelo teor de água em solos argilosos. $\mathrm{O}$ aumento da profundidade de trabalho fez com que o escarificador exigisse $11,6 \%$ a mais de força na barra de tração, evidenciando o efeito da resistência do solo sobre o equipamento de hastes. Fernandes \& Gamero (2010) trabalharam com escarificador de 7 hastes conjugado com discos de cortes flutuantes em trator de $89 \mathrm{~kW}$, com teor de água do solo de $29,6 \% \mathrm{e}$ profundidade de trabalho de $0,15 \mathrm{~m}$, na implantação da cultura do girassol e encontraram valores de força de tração de $41,6 \mathrm{kN}$, em nitossolo vermelho distroférrico típico A moderado, textura argilosa. Os valores de força de tração encontrados foram 126\% superiores, pois trabalharam em área com onze anos de plantio direto, diferente da área do presente experimento que foi preparada, anteriormente, com grade pesada para a implantação da cultura do milho no ano anterior.

A potência demandada na barra de tração apresentou comportamento semelhante à força de tração, ou seja, houve diferença no fator profundidade de trabalho, sendo que o aumento da profundidade exigiu maior potência. $\mathrm{O}$ teor

Quadro 2. Desdobramento da interação entre os fatores teor de água do solo e profundidade de trabalho para a variável velocidade de trabalho

\begin{tabular}{lcc}
\hline & \multicolumn{2}{c}{ Teor de água do solo (\%) } \\
\cline { 2 - 3 } & $\mathbf{2 6 , 2}$ & $\mathbf{2 1 , 9}$ \\
\hline Profundidade de trabalho & \\
$0,20 \mathrm{~m}$ & $3,91 \mathrm{~A} \mathrm{~b}$ & $3,93 \mathrm{~A} \mathrm{a}$ \\
$0,30 \mathrm{~m}$ & $3,81 \mathrm{~A} \mathrm{a}$ & $3,95 \mathrm{~B} \mathrm{a}$ \\
\hline
\end{tabular}

Médias seguidas de mesmas letras maiúsculas nas linhas e minúsculas nas colunas não diferem entre si, pelo teste de Tukey, a 5\% de probabilidade. 
de água no solo não alterou a potência, exigindo demanda média do trator de $19,9 \mathrm{~kW}$. Salvador et al. (2008), trabalhando com subsolador de 3 hastes em nitossolo vermelho distroférrico textura argilosa, em condição de solo escarificado, obtiveram valores de potência na barra de tração da ordem de 19,0 kW. Apesar de haver diferenças para a profundidade de trabalho, esse valor foi inferior à $2 \mathrm{~kW}$, quando comparadas as médias, o que, para o trator que estava tracionando o escarificador, que possui $91,9 \mathrm{~kW}$ de potência máxima no motor, pode ser considerada como irrisório.

Para a Cco, houve diferença somente para o teor de água do solo, sendo maior quando o solo estava mais seco e na profundidade de trabalho de $0,30 \mathrm{~m}$, fato esse explicado pela maior velocidade do conjunto trator-escarificador devido a menor resistência ao rolamento. Para o fator profundidade de trabalho, não houve diferenças.

Quanto a patinagem dos rodados, os valores ficaram dentro ou abaixo dos índices preconizados pela ASAE (2003), para solo firme, que é de 8 a 10\%, evidenciando que o trator estava com lastro acima do recomendado para o trabalho com escarificador, podendo haver remoção de lastro. Outro fator que pode explicar os valores de patinagem é que o equipamento exigiu potência abaixo da que está disponível pelo trator usado no experimento. Os rodados traseiros não sofreram influência tanto do teor de água quanto da profundidade de trabalho. Nos rodados dianteiros, houve diferença, em que o solo com maior teor de água fez com que os pneus patinassem mais, bem como na maior profundidade de trabalho.

\section{CONCLUSÕES}

- O aumento no teor de água do solo proporcionou ao conjunto trator-escarificador menor consumo horário de combustível, menor patinagem dos rodados dianteiros, menor capacidade de campo operacional e maior consumo de combustível operacional.

- A maior profundidade de trabalho do escarificador aumentou o consumo horário e operacional de combustível, força de tração e potência na barra e patinagem dos rodados dianteiros.

\section{AGRADECIMENTOS}

À CAPES (Coordenação de Aperfeiçoamento de Pessoal de Nível Superior) pela concessão de bolsa de mestrado para o primeiro e quinto autores.

\section{REFERÊNCIAS BIBLIOGRÁFICAS}

ANDREOLI, I.; CENTURION, J. F. Levantamento detalhado dos solos da Faculdade de Ciências Agrárias e Veterinárias de Jaboticabal. In: CONGRESSO BRASILEIRO DE CIÊNCIA DO SOLO, 27. Anais... Brasília: Sociedade Brasileira de Ciência do solo, 1999. 32p.

ASAE - AMERICAN SOCIETY OF AGRICULTURAL ENGINEERS. Terminology and definitions for agricultural tillage implements. In: ASAE, Standards 2003: standards engineering practices data. St. Joseph, 2003. p.373-380.

EMBRAPA. EMPRESA BRASILEIRA DE PESQUISA AGROPECUÁRIA. Manual de métodos de análise do solo. $2^{\mathrm{a}}$ ed. Rio de Janeiro: EMBRAPA, 1997. 212p.

FERNANDES, J.C.; GAMERO, C.A. Avaliação do desempenho das máquinas agrícolas na implantação da cultura do girassol. Energia na Agricultura, Botucatu, v.25, n.2, p.74-87, 2010.

FERREIRA, D.F. SISVAR: um programa para análises e ensino de estatística. Revista Symposium, Lavras, v.6, n.1, p.36-41, 2008.

GABRIEL FILHO, A.; LANÇAS, K. P.; GUERRA, S. P.; PAULA, C. A.; MONTEIRO, L. A. Umeb - unidade móvel para ensaio da barra de tração. Engenharia Agrícola, Jaboticabal, v.28, n.4, p.782-789, 2008.

KICHLER, C.M.; FULTON, J.P.; RAPER, R.L.; ZECH, W.C.; McDONALD, T.P.; BRODBECK, C.J. Spatially monitoring tractor performance to evaluate energy requirements of variable depth tillage and implement selection. In: ASABE ANNUAL INTERNATIONAL MEETING., 2007, Minneapolis, Proceedings... St. Joseph: ASABE, 2007. Paper Number: 071028. 
KÖEPPEN, W. Climatologia: con um estúdio de los climas de la Tierra. México: Fondo de Cultura Economica, 1948. 478p.

LEVIEN, R.; GAMERO, C.A.; FURLANI, C.E.A. Preparo convencional e reduzido em solo argiloso em diferente condições de cobertura de inverno. Engenharia Agrícola, Jaboticabal, v.23, n.2, p.277-289, 2003.

MONTEIRO, L.A. Desempenho operacional e energético de um trator agrícola em função do tipo de pneu, velocidade de deslocamento, lastragem líquida e condição superficial do solo. 2008. 69f. Dissertação (Mestrado em Agronomia) - Faculdade de Ciências Agronômicas, UNESP Botucatu, SP, 2008.

REIS,E.F.;VIEIRA,L.B.;SOUZA,C.M.;SCHAEFER, C.E.G.R.; FERNANDES, H.C. Avaliação do desempenho de duas semeadoras-adubadoras de plantio direto em diferentes teores de água em um solo argiloso. Engenharia na Agricultura, Viçosa, v.10, n.1-4, p.61-68, 2002.

SALVADOR, N.; BENEZ, S.H.; MION, R.L. Consumo de combustível na operação de subsolagem realizada antes e depois de diferentes sistemas de preparo periódico do solo. Engenharia Agrícola, Jaboticabal, v.28, n.2, p.256-62, 2008.

SASAKI, C.M.; GONÇALVES, J.L.M.; Desempenho operacional de um subsolador em função da estrutura, do teor de argila e de água em três latossolos. Scientia Forestalis, Piracicaba, n.69, p.115-124, 2005.

SPOOR, G.; GODWIN, R.J. An experimental investigation into the deep loosening of soil by rigid tines. Journal of agriculture engineering research, v.23, p.243-258, 1978. 